In Chull Jang and Lee Jin Choi*

\title{
Staying connected during COVID-19: The social and communicative role of an ethnic online community of Chinese international students in South Korea
}

https://doi.org/10.1515/multi-2020-0097

\begin{abstract}
As the public health threat posed by the COVID-19 pandemic is still evolving globally, many linguistic minorities are struggling to obtain accurate and timely health information about the disease and its prevention and treatment in their native language. This study argues that existing ethnic online communities can play an important role in dealing with such health information disparities in the wake of the COVID-19 pandemic. By analyzing the activities and postings on an online community of Chinese international students in South Korea, this paper illustrates that the community functions as a virtual hub that produces and disseminates up-to-date and essential information about COVID-19 and provides a platform for users to share experiences and emotions accompanying the unprecedented situation. This study points out that the participation of Chinese international students in the online community is voluntary and based on established infrastructure because of the presence of a greater number of Chinese students in South Korea. Thus, it urges the government and local authorities to be more aware of the importance of providing adequate support and guidance to linguistic minorities in such uncertain and frightening times.
\end{abstract}

Keywords: social media, online community building, language brokering, disaster communication, health communication, COVID-19

\section{Background}

Facing the COVID-19 outbreak, the government of South Korea has taken quick and decisive action to contain the spread of the virus. Utilizing the country's

*Corresponding author: Lee Jin Choi, Department of English Education, Hongik University, Seoul, South Korea, E-mail: choileejin@gmail.com. https://orcid.org/0000-0002-3407-6367

In Chull Jang: Department of English Language and Culture, Konkuk University - Chungju Campus, Chungju, South Korea 
information technology and biotechnology infrastructure, the South Korean government has employed a preemptive strategy of identifying and isolating patients through widespread and large-scale testing of those with symptoms or those who might have come in contact with infected people (The Government of the Republic of Korea 2020). The key element of this strategy is "contact tracing," that is, tracing movements of infected people and identifying transmission of COVID-19. To maximize the effectiveness of this strategy, the government releases basic information about COVID-19 and prevention measures, data about new patients, outbreak trends, and relevant policies on a daily basis, as well as details about each confirmed patient's travel history, consequently leading to the production and circulation of an ever greater amount of information in various forms.

As South Korea transforms into a multilingual and multicultural society, the government is trying to provide multilingual resources in the wake of COVID-19, such as public health posters and interpretation service hotlines. However, for non-Korean speaking residents, obtaining up-to-date and real-time information about the constantly changing situation of COVID-19 in South Korea remains a major challenge. When the number of confirmed cases started to soar in late February 2020, and the crisis turned into an epidemic at the local level, non-Korean speakers struggled to access information about the travel routes of confirmed patients in their vicinity or about store locations and stock status of face masks, whose distribution the government centralized because of high demand. It was not until late March that the government launched English and Chinese versions of its official COVID-19 website (http://ncov.mohw.go.kr/). While the English version includes information regarding daily briefings, updates on the infection situation, and correction of fake news, the Chinese version simply offers basic information about COVID-19 and its preventive measures. Moreover, public alert messages sent to mobile phones to inform users about travel routes of confirmed patients and other essential preventive measures are still only being provided in Korean.

As the public health threat posed by COVID-19 still looms large, it is vital to provide accurate and timely information about the disease, and its prevention and treatment, to not only contain the spread of the outbreak, but also to cope with fear and uncertainty on a personal level (c.f., Comfort et al. 2004; Paton and Irons 2016). However, linguistic minorities worldwide are struggling to obtain such health information in their native language (Avineri et al. 2018; Briggs 2018; Flood et al. 2018; Rubin 2014). Focusing on the case of Chinese international students in South Korea, this paper reports that the ethnic online community plays an important role in dealing with health information disparities in the COVID-19 pandemic. More specifically, by analyzing the activities and postings on an online community of Chinese international students in South Korea, this paper suggests that the ethnic online community functions as a hub for producing and disseminating up-to-date 
and essential information about COVID-19 and provides a platform for users to share experiences and emotions accompanying this unprecedented situation.

\section{The study}

Many universities in East Asia have been actively recruiting international students to enrich campus diversity, increase their revenue stream, and enhance their competitiveness in both domestic and global higher education markets. South Korea, as one of the leading countries internationalizing higher education in the region, has emerged as the prominent destination for international students from other Asian countries (Jon et al. 2014). The number of international students enrolled in colleges and universities in South Korea reached over 160,165 in 2019, compared to 75,850 in 2009 and 3,418 in 1999 (Korean Educational Statistics Service 2019). As of the 2019 academic year, the home countries of international students in South Korea were China (44.4\%), Vietnam (23.4\%), Mongolia (4.6\%), Japan (2.7\%), and the United States (1.8\%). Although the Chinese population includes speakers from diverse linguistic backgrounds, South Korean universities tend to assume that Chinese international students have native (-like) competence in Mandarin Chinese.

Our interest in Chinese international students stemmed from our experiences as faculty members in South Korean universities. The two universities to which we are affiliated rank among the top 10 in South Korean higher education in terms of the number of enrolled international students, with Chinese students accounting for over 70\% of the total. Thus, after the outbreak of COVID-19 in China in January 2020, we were led to observe how the South Korean government and universities responded to Chinese students who were planning to enter South Korea for the 2020 spring semester. However, the rapid spread of COVID-19 in South Korea in late February shifted our focus toward how the Chinese international students already staying in South Korea were dealing with this situation. The students expressed fear and anxiety not only because their status in South Korea was unstable but also because the earlier outbreak in China had made them keenly aware of its seriousness. Through our immediate fieldwork with Chinese international students on campus, we learned that though they employed a variety of sources to access information about the pandemic, Fenhan (http://www.icnkr.com/), 奋斗在韩国, meaning "struggles in Korea" or "working hard in Korea”, an online community for Chinese international students in South Korea, was a key website that actively mediated and produced information about the outbreak.

With more than 2.5 million members and an average of 10,000 daily visitors, Fenhan is considered the most useful and popular website among Chinese 


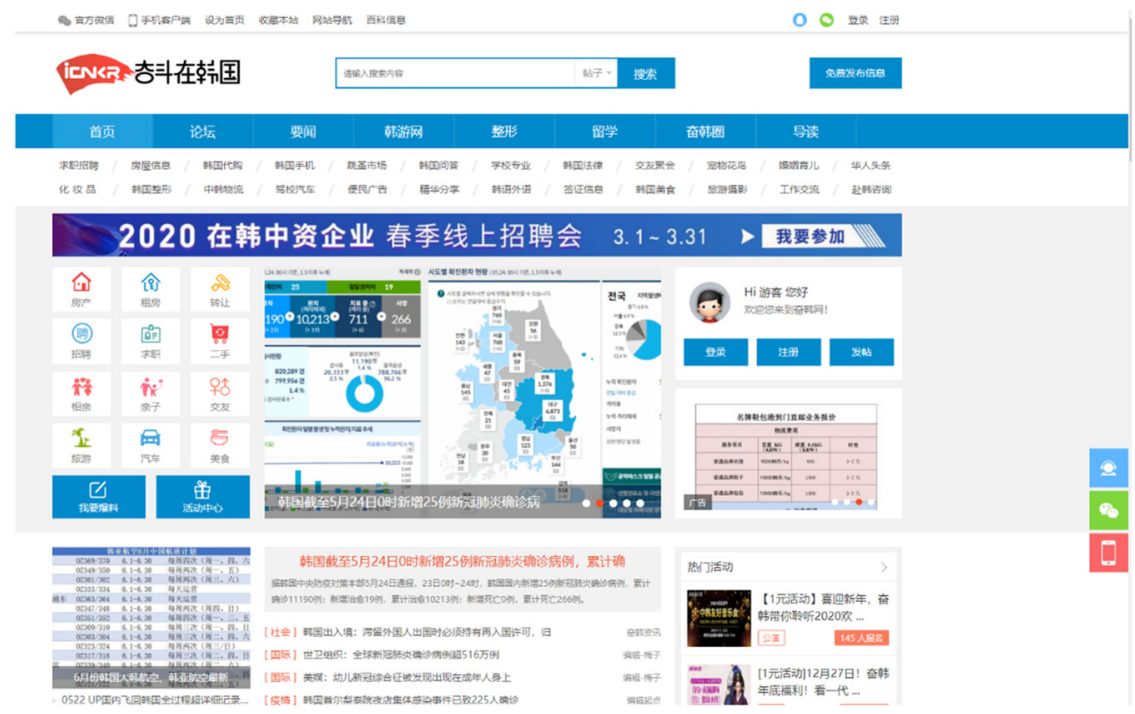

Figure 1: Fenhan homepage.

international students in South Korea. It serves as a virtual hub to share information on life and study in South Korea, containing multiple sections such as "news," "housing," "jobs," "Korean Q\&A," "studying in South Korea," "visa issues," "Korean food," "travel," and "flea markets" and links to ethnic businesses (see Figure 1). Its mobile application, Weibo group page, and WeChat account offer mobile users easy access to postings, which can also be shared on other mobile platforms.

After the COVID-19 outbreak, the administrators and editors of Fenhan started posting news articles about the pandemic in the news forum section and even created a special discussion board titled “COVID-19 in South Korea” (新冠肺炎韩 国协调). This board offers three services, “buy," “sell,” and “discussion and volunteering," allowing members to buy and sell items such as face masks and hand sanitizers, seek clarification regarding the outbreak, express their concerns and emotions, and share their experiences of getting tested and mandatory selfquarantine. In the beginning, as Mainland China confronted the pandemic, members of the online community actively engaged to support China (e.g., by sending face masks to China) and help Chinese students who were about to enter South Korea (e.g., by giving information about visas, quarantine, and universities' plans). However, as the number of COVID-19 patients soared in South Korea, the members started to focus more on monitoring and discussing the situation within the country. 
To examine the role of this ethnic online community during the COVID-19 pandemic, we first selected two sections as sites of analysis: articles tagged with "epidemic" in news forum and postings published in "discussion and volunteering" section of "COVID-19 in South Korea." Then we analyzed the postings and the comments on these posts after February 18, 2020, when South Korea entered a new phase with the 31st confirmed case of a patient identified as a super spreader, which resulted in uncertain circumstances requiring timely and accurate information for the public. Drawing on interactional sociolinguistics (Gumperz 1982) and digital ethnography (Varis 2016), the analysis aimed to explore what communicative functions these postings demonstrated and what role the online community played in terms of disaster and medical communication.

\title{
3 The news forum: Moderating and producing information
}

With the outbreak and spread of COVID-19, first in China and later in South Korea, the website's administrators, editors, and volunteers did their best to provide Chinese students studying in South Korea with real-time and accurate information about the virus, preventative measures, changing health and visa policies, and the evolving public health crisis. For this purpose, they voluntarily took on the role of "language broker" (Tse 1996); that is, they not only transmitted but also mediated relevant information from Korean into Chinese. They stated their mission as follows:

\begin{abstract}
Since the outbreak of COVID-19 in South Korea, Fenhan has been collecting daily news about the situation in South Korea, releasing relevant information, editing and translating reports and important announcements from Korean and Chinese governments, and summarizing the travel routes and contacts of confirmed cases. With the help of volunteers, Fenhan has provided Chinese international students and Chinese communities in South Korea with information on the coronavirus disease. Because of the accuracy and reliability of information, the website has been lauded by users. Currently, Fenhan is the most popular online source to get the latest news about coronavirus for Chinese people studying and living in Korea. The website gets more than 100,000 views daily on news about the coronavirus in South Korea. (04/24/2020, http://bbs.icnkr.com/forum.php?mod $=$ viewthread\&tid $=6921251)^{1}$
\end{abstract}

In fact, the administrators quickly translated the information released by the South Korean government or the press. In addition, they constantly offered advice and guidance about preventative rules and the stepwise process of getting tested when

1 All the translations in this article were made by a Chinese-English bilingual and cross-checked by two other Chinese-English bilinguals. 
symptoms appear. They also posted a summary of the Korea Centers for Disease Control and Prevention daily briefings about new patients and infections, which was key to understanding the pandemic situation in South Korea. Among all postings, these summaries got the largest numbers of views and replies, indicating Chinese international students' urgent need for such information and concerns about the pandemic.

Their mediating role as language brokers further led to the selection and highlighting of certain topics and multimodal remediation of key information. Considering the living and job status of the majority of the visitors, the website attended to topics such as university course schedules (as many universities postponed the start of the spring semester and later decided to offer online classes only), visa and immigration polices (as regulations on in-bound entry and quarantine were constantly updated), and messages from the Chinese embassy. The characteristic of online communication facilitating multimodal remediations (Thurlow and Jaworski 2014) enabled the administrators and editors to transform health information into visuals or other electronic forms accessible or sharable among other mobile devices or online platforms (See Figure 2).

One notable characteristic of this news forum in terms of disseminating health information is that only administrators and editors are permitted to post on the forum. They justified this exclusive authorship as follows:

Fenhan reminds you that during the outbreak in South Korea, social media or individuals posting fake news and spreading rumors will negatively influence the public and the relationship between Chinese and Korean communities. We hope that nobody will spread or believe rumors and that everyone will share accurate information. This will help our battle against the virus.

(02/27/2020, http://bbs.icnkr.com/forum.php?mod = viewthread\&tid = 6921251)

This closed group of authors and moderators contributed to circulating reliable information, which established their authority in the community (Angouri and Sanderson 2016). Building on their established authority, they often took on more proactive roles than language brokers by not only disseminating but also producing information. They published a special report on the epidemic situation in South Korea (http://bbs.icnkr.com/thread-6867520-1-1.html), arranged a poll asking about individual responses under exacerbating pandemic circumstances (http://bbs.icnkr.com/thread-6844016-1-1.html), and created a list of Korean expressions related to the pandemic situation (http://bbs.icnkr.com/thread6835586-1-1.html). The results of the poll, in which 5240 users participated, showed that Chinese international students were more willing to self-isolate than return to China. The bilingual list included useful words about preventive items and symptoms and simple but key expressions for communication in work or 

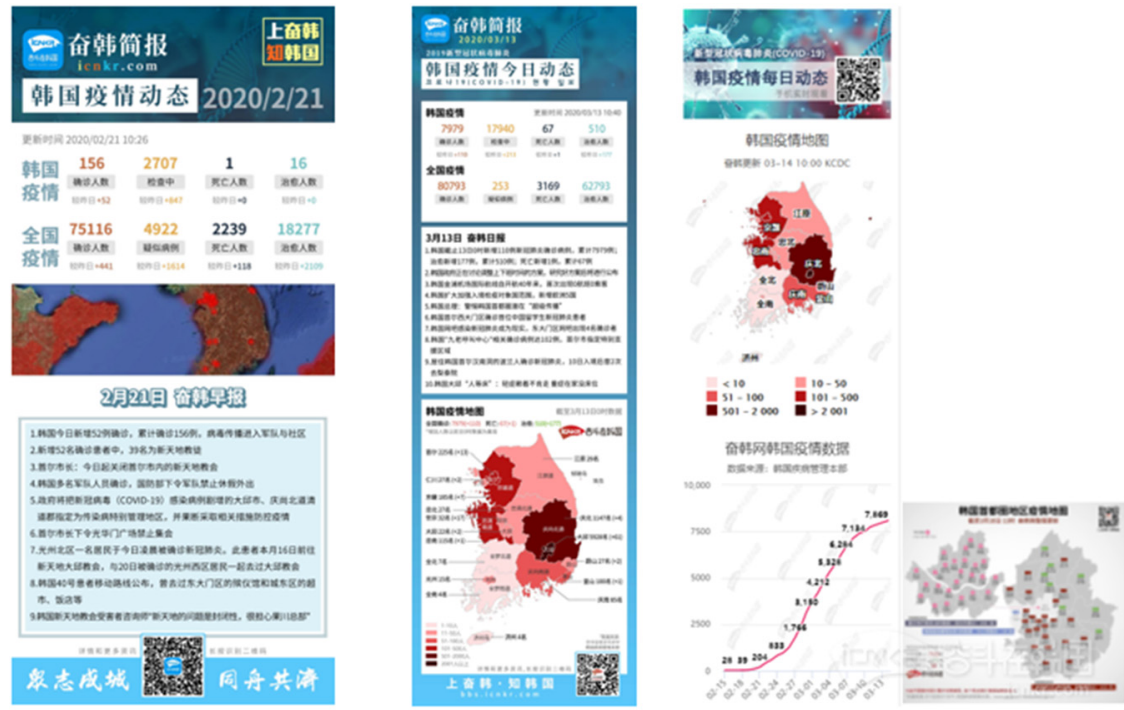

Figure 2: Multimodal remediations of COVID-19 information (Source: http://bbs.icnkr.com/ forum. php? mod $=$ viewthread\&tid $=6921251$ ).

medical situations. This produced information generated responses of gratitude and support from users for its timely and pragmatic contributions.

\section{The discussion board: Creating a community of care and solidarity}

Previous studies on the role of online communities in disaster communication have demonstrated that online communities and social media play an important role in creating a sense of community spirit and solidarity among members under uncertain circumstances including natural or human-made disasters (e.g., Acar and Muraki 2011; Hjorth and Kim 2011; Macias et al. 2009; Paton and Irons 2016; Qu et al. 2009). Fenhan not only provides a space for information gathering and sharing, but also serves as a platform for Chinese international students to seek advice and emotional support in this uncertain and frightening time. The role of community building became particularly prominent as the outbreak spread in South Korea and social distancing and 14-day mandatory quarantine for all entrants from overseas separated people and limited their movement. 
A considerable portion of postings and discussion threads we analyzed include Chinese international students discussing the latest information about the outbreak and confirmed cases, seeking advice surrounding the on-going situation, and sharing their own experiences of getting tested and being quarantined. The following posting and its discussion thread show how these students, using the ethnic online community, not only seek and provide advice on what to do, but also offer emotional help to fellow Chinese student who "got really panicky." The posting was shared on February 24, 2020, a day after the South Korean government raised its coronavirus alert to the highest level.

All names have been Shall I return to China or stay in Korea?... Yesterday, I was chosen: coughing a little (இ $\omega$ இ)... I got really panicky. (...)

Jihad for Love: $\quad$ Don't burden the motherland, stay in South Korea. My friend, pay more attention to safety and use protective products, and try to avoid going out or going to places with many people.

Queqiao: $\quad$ I would go back to China but I am telling you that the virus has widely spread in many places ... My friend, please be careful!

(02/24/2020, http://bbs.icnkr.com/thread-6835217-1-1.html)

It is noteworthy that both users named "Jihad for love" and "Queqiao" used the term “friend” (朋友) to refer to the other user while providing advice and comfort, suggesting that online communication occurs in the context where a sense of connectedness and belonging is highly promoted.

In addition, the Chinese international students actively utilize the postings and discussion threads to express their personal feelings of anger, anxiety, frustration, and fear, and seek and provide emotional support to cope with the current situation. The following excerpt illustrates how the students instantly created a supportive community via online discussion threads for a fellow student who felt rejected and frustrated.

Buns in a bowl: $\quad$ A friend of mine even said to me that I should not come back to China [because I could be a potential carrier of the virus due to the recent dramatic spread of coronavirus in South Korea]. Do you guys think what she said makes sense ... we shouldn't go back [to China]? We should stay here and die. 
Extraterrestrial Don't be afraid. It's just one person's opinion. superhero:

Formalin:

Everyone has their own personalities and perspectives but that does not mean they have the right to say whatever they want to say to other people. They are afraid that we will bring the virus back, and we are afraid that they will be infected and left unattended. What we are having here is the lack of consideration for each other....Stay strong!

(02/25/2020, http://bbs.icnkr.com/thread-6836277-1-1.html)

Empathy and encouragement offered by the users in the above excerpt suggest that ethnic online communities can provide an alternative space for interpersonal communication and mutual help in terms of disaster management (c.f., Kim and Hastak 2018).

\section{Discussion and conclusion}

This article has illustrated that in the wake of the COVID-19 pandemic, the online community for Chinese international students in South Korea serves as a virtual space for language brokering and trust development among migrants, who likely feel insecure due to language barriers and citizenship status. In the early stages of the outbreak in South Korea, Chinese students had already observed or experienced how the virus would affect their everyday life from its outbreak in China and thus had a high level of concern. Through the online community, they address the health information gap by sharing, producing, and disseminating up-to-date information, and building a community of care and solidarity by comforting and providing emotional support to each other. This study suggests that, in pandemic situations, existing ethnic online communities can be transformed into a space to serve communicative and emotional functions corresponding to other online communities for patients or victims of natural disasters (e.g., Acar and Muraki 2011; Angouri and Sanderson 2016; Baxter 2018; Macias et al. 2009; Qu et al. 2009).

It is, however, important to note that the community's ability to mediate information and address feelings of fear and uncertainty lies in the infrastructure as a result of the presence of a greater number of Chinese students in South Korea (c.f., Xiang and Lindquist 2014). Their social and economic capital enabled such an online community to launch and develop, which in turn played an important role in the current crisis through administrators' leadership and users' active participation. The other language minorities in South Korea or elsewhere might not be 
able to form an ethnic online community as they do not necessarily have enough social capital to do so. Thus, further attention should be given to the ways in which linguistic minorities with less leverage and social capital deal with the issue of information discrepancy during an outbreak (Briggs 2018; Flood et al. 2018). In addition, this study's focus on communicative functions and roles does not mean that this online community is ideologically a void and neutral space for such discourse (Heller 2001). A number of postings and responses contain evaluative comments on policies related to COVID-19 initiated by Chinese, South Korean, and even U.S. governments, and the hygiene behaviors of those ethnic groups. The discourse analysis of these comments will reveal how the pandemic situation can potentially lead to the production and/or perpetuation of certain normative ideologies of ethnicity and nationalism in relation to the discourse on public health and disease (McElhinny 2005).

Like many national governments and local authorities across the world who have tried to provide adequate information and guidance relating to the COVID-19 outbreak, the South Korean government has made efforts to provide up-to-date information utilizing various digital tools such as mobile applications, websites, and public alert messages (The Government of the Republic of Korea 2020). However, most of the information has been provided only in Korean, which leads to discrepancies in information and guidance between Korean language speakers and other language minorities in South Korea. Even though it seems that Chinese international students have been coping with the language and communication issues quite successfully through their well-organized online community, it must be noted that their participation in the online community is voluntary and based on the condition of belonging to the ethnic group. We are convinced that it is equally important for the government and local authorities to be more aware of this apparent discrepancy, and to rethink how to provide adequate support and guidance to language minority groups in times of crisis (Avineri et al. 2018; Piller 2016).

Acknowledgments: We would like to thank Matthew Zhaohai Hu, Jaeiyoung Jang, Zhuolin Liu, and Lian Jun Yang for their assistance with the fieldwork and translation. We also extend our gratitude to Jinsuk Yang, the editors of this special issue, and two anonymous reviewers for their constructive feedback.

Research funding: This research was supported by the 2020 Hongik Faculty Research Support Fund. 


\section{References}

Acar, Adam \& Yuya Muraki. 2011. Twitter for crisis communication: Lessons learned from Japan's tsunami disaster. International Journal of Web Based Communities 7(3). 392-402.

Angouri, Jo \& Tessa Sanderson. 2016. 'You'll find lots of help here': Unpacking the function of an online Rheumatoid Arthritis (RA) forum. Language \& Communication 46. 1-13.

Avineri, Netta, Laura R. Graham, Eric J. Johnson, Robin C. Riner \& Jonathan Rosa. 2018. Introduction: Reimagining language and social justice. In Netta Avineri, Laura R. Graham, Eric J. Johnson, Robin C. Riner \& Jonathan Rosa (eds.), Language and social justice in practice, 1-16. New York: Routledge.

Baxter, Judith. 2018. 'Keep strong, remember everything you have learnt': Constructing support and solidarity through online interaction within a UK cancer support group. Discourse \& Society 29(4). 363-379.

Briggs, Charles L. 2018. Language, justice, and rabies. In Netta Avineri, Laura R. Graham, Eric J. Johnson, Robin C. Riner \& Jonathan Rosa (eds.), Language and social justice in practice, 109-118. New York: Routledge.

Comfort, Louise K., Kilkon Ko \& Adam Zagorecki. 2004. Coordination in rapidly evolving disaster response systems: The role of information. American Behavioral Scientist 48(3). 295-313.

Flood, David, Anita Chary, Peter Rohloff \& Brent Henderson. 2018. Language as health: Healing in indigenous communities in Guatemala through the revitalization of Mayan languages. In Netta Avineri, Laura R. Graham, Eric J. Johnson, Robin C. Riner \& Jonathan Rosa (eds.), Language and social justice in practice, 136-143. New York: Routledge.

Gumperz, John J. 1982. Discourse strategies. Cambridge: Cambridge University Press.

Heller, Monica. 2001. Critique and sociolinguistic analysis of discourse. Critique of Anthropology 21(2). 117-141.

Hjorth, Larissa \& Kyoung-Hwa Yonnie Kim. 2011. Good grief: The role of social mobile media in the 3.11 earthquake disaster in Japan. Digital Creativity 22(3). 187-199.

Jon, Jae-Eun, Jenny J. Lee \& Kiyong Byun. 2014. The emergence of a regional hub: Comparing international student choices and experiences in South Korea. Higher Education 67(5). 691710.

Kim, Jooho \& Makarand Hastak. 2018. Social network analysis: Characteristics of online social networks after a disaster. International Journal of Information Management 38(1). 86-96.

Korean Educational Statistics Service. 2019. sidobyeol guggabyeol godeung-gyoyuggigwan oegug-in yuhagsaeng hyeonhwang [Current status of international students in tertiary education institutions by country]. https://kess.kedi.re.kr/post/6691509? item Code=03\&menuld=m_02_03_03 (accessed 25 June 2020).

Macias, Wendy, Karen Hilyard \& Vicki Freimuth. 2009. Blog functions as risk and crisis communication during hurricane Katrina. Journal of Computer-Mediated Communication 15(1). 1-31.

McElhinny, Bonnie. 2005. 'Kissing a baby is not at all good for him': Infant mortality, medicine, and colonial modernity in the U.S.-Occupied Philippines. American Anthropologist 107(2). 183-194.

Paton, Douglas \& Melanie Irons. 2016. Communication, sense of community, and disaster recovery: A facebook case study. Frontiers in Communication 1(4). https://www.frontiersin. org/articles/10.3389/fcomm.2016.00004/full (accessed 5 June 2020). 
Piller, Ingrid. 2016. Linguistic diversity and social justice: An introduction to applied sociolinguistics. New York: Oxford University Press.

Qu, Yan, Philip F. Wu \& Xiaoqing Wang. 2009. Online community response to major disaster: A study of Tianya forum in the 2008 Sichuan earthquake. In 2009 42nd Hawaii International Conference on System Sciences, 1-11. Big Island: IEEE.

Rubin, Donald. 2014. Applied linguistics as a resource for understanding and advancing health literacy. In Heidi E. Hamilton \& Wen-ying Sylvia Chou (eds.), The Routledge handbook of language and health communication, 153-167. New York: Routledge.

The Government of the Republic of Korea. 2020. Flattening the curve on COVID-19: How Korea responded to a pandemic using ICT. http://www.korea.kr/common/download.do? fileld=190536078\&tblKey=GMN (accessed 28 May 2020).

Thurlow, Crispin \& Adam Jaworski. 2014. 'Two hundred ninety-four': Remediation and multimodal performance in tourist placemaking. Journal of SocioLinguistics 18(4). 459-494.

Tse, Lucy. 1996. Language brokering in linguistic minority communities: The case of Chinese- and Vietnamese-American students. Bilingual Research Journal 20 (3-4). 485-498.

Varis, Piia. 2016. Digital ethnography. In Alexandra Georgakopoulou \& Tereza Spilioti (eds.), The Routledge handbook of language and digital communication, 55-68. New York: Routledge.

Xiang, Biao \& Johan Lindquist. 2014. Migration infrastructure. International Migration Review 48 (1 Suppl). S122-S148. 